University of Nebraska - Lincoln

DigitalCommons@University of Nebraska - Lincoln

Nebraska Cooperative Fish \& Wildlife Research Nebraska Cooperative Fish \& Wildlife Research Unit -- Staff Publications

2003

\title{
Estimation of Fishing Tournament Mortality and Its Sampling Variance
}

Gene R. Wilde

Texas Tech University, gene.wilde@ttu.edu

Kevin L. Pope

University of Nebraska-Lincoln, kpope2@unl.edu

Richard E. Strauss

Texas Tech University

Follow this and additional works at: https://digitalcommons.unl.edu/ncfwrustaff

Part of the Other Environmental Sciences Commons

Wilde, Gene R.; Pope, Kevin L.; and Strauss, Richard E., "Estimation of Fishing Tournament Mortality and Its Sampling Variance" (2003). Nebraska Cooperative Fish \& Wildlife Research Unit -- Staff Publications. 90.

https://digitalcommons.unl.edu/ncfwrustaff/90

This Article is brought to you for free and open access by the Nebraska Cooperative Fish \& Wildlife Research Unit at DigitalCommons@University of Nebraska - Lincoln. It has been accepted for inclusion in Nebraska Cooperative Fish \& Wildlife Research Unit -- Staff Publications by an authorized administrator of DigitalCommons@University of Nebraska - Lincoln. 


\title{
Estimation of Fishing Tournament Mortality and Its Sampling Variance
}

\author{
Gene R. Wilde* and Kevin L. Pope \\ Wildlife and Fisheries Management Institute, Mail Stop 2125, \\ Texas Tech University, Lubbock, Texas 79409, USA \\ Richard E. Strauss \\ Department of Biology, Texas Tech University, Lubbock, Texas 79409, USA
}

\begin{abstract}
The mortality of fish captured in fishing tournaments has commonly been estimated incorrectly and, thus far, only one account has presented an estimate of the standard error or confidence interval for tournament-associated mortality. In this article we describe methods for estimating the initial, delayed, and total mortality of tournament-caught fish and provide formulae for estimating the sampling variances of these estimates. The absence of such estimates from previous studies may explain an observed lack of change in tournament-associated mortality between the 1980s and the 1990s. Our methods provide insight into the design of studies of tournament-associated mortality and suggest, for example, that many previous studies have held too few fish for observation and have greatly undersampled control fish. Improved study design and reporting should increase our understanding of the factors influencing tournament-associated mortality.
\end{abstract}

Fishing tournaments commonly require live release of captured fishes after weigh-in. This practice initially was adopted to reduce potential biological and social impacts of fishing tournaments (Holbrook 1975; Barnhart 1989) and assumes that a substantial proportion of angler-caught fish survives capture, handling, and release (e.g., Muoneke and Childress 1994). To date, at least 20 studies have examined tournament-associated mortality in black basses Micropterus spp. to assess this assumption, measure the magnitude of tournamentassociated mortality, and develop methods for further reducing mortality (Wilde 1998). Other studies have also examined the tournament-associated mortality of walleye Stizostedion vitreum and sauger S. canadense (e.g., Goeman 1991; Fielder and Johnson 1994; Hoffman et al. 1996). Still other studies will likely extend to additional species because of the growth in popularity of tournament angling (Shupp 1979; Duttweiler 1985; Schramm et al. 1991) and concerns for potential fishery effects of tournaments (Schramm et al. 1991; Wilde et al. 1998a).

The mortality of tournament-caught fish usually is recorded at weigh-in because most tournaments are conducted with rules that penalize anglers for dead fish (e.g., Kwak and Henry 1995; Hoffman et al. 1996; Wilde et al. 1998b, 2002b). Mortality

* Corresponding author: gene.wilde@ttu.edu

Received April 3, 2002; accepted November 9, 2002 that occurs at or before weigh-in is variously referred to as initial mortality, prerelease mortality, and weigh-in mortality. Not all released fish survive capture, holding in live wells, and weigh-in (e.g., Holbrook 1975); therefore, several studies also have measured delayed mortality (also referred to as postrelease mortality), which occurs after tournament-caught fish are released. Generally, a sample of tournament-caught fish is collected at the release site, held in ponds, cages, or pens, and observed for several days to estimate mortality that released fish might be expected to suffer. Estimates of total tournament-associated mortality are obtained by combining estimates of initial and delayed mortality.

Among the papers reviewed by Wilde (1998) that estimated total mortality in black bass tournaments and that clearly stated the methods for that calculation, several presented incorrect estimates of total mortality (May 1973; Schramm et al. 1985; and Gilliland 1997, among others). None provided an estimate of the sampling variance of total mortality. Herein, we present methods for estimating total mortality of tournament-caught fish and provide formulae for estimating the sampling variance of such estimates. We also comment on the design of studies for measuring mortality of fishes captured in tournaments.

\section{The Problem}

Consider a hypothetical 2-d fishing tournament (Table 1). On the first day of the tournament, 1,258 
TABLE 1.- Results for a hypothetical fishing tournament showing calculation of the quantities necessary for estimation of total mortality and its sampling variance. Fisher's exact test of the hypothesis $M_{T} \geq M_{C}$ yielded $P$-values of 0.02 on day 1 and 0.05 on day 2; therefore, $M_{D(T)}>0$ on both days. Because the number of tournament-caught fish held for observation was small compared with the total number captured, a finite population correction factor was not used. Mortality, sampling variances, and standard error estimates are presented here as proportions; to express them as percentages they must be multiplied by 100 (mortality, standard errors) or $100^{2}$ (variances).

\begin{tabular}{|c|c|c|c|c|c|}
\hline Variable & Symbol & $\begin{array}{c}\text { Day 1 } \\
\text { (pen A) }\end{array}$ & $\begin{array}{c}\text { Day } 2 \\
\text { (pen B) }\end{array}$ & Total & $\begin{array}{c}\text { Equation } \\
\text { in text }\end{array}$ \\
\hline Total fish captured & $N_{(T)}$ & 1,258 & 938 & 2,196 & \\
\hline Number alive at weigh-in & $n_{L(T)}$ & 1,050 & 853 & 1,903 & \\
\hline Number dead at weigh-in & $n_{I(T)}$ & 208 & 85 & 293 & \\
\hline Initial mortality & $M_{I(T)}$ & 0.165 & 0.091 & 0.133 & 1 \\
\hline Tournament fish held for delayed mortality & $N_{T(T)}$ & 30 & 30 & & \\
\hline Control fish held for delayed mortality & $N_{C}$ & 30 & 30 & & \\
\hline Tournament fish dying as delayed mortality & $n_{T(T)}$ & 9 & 6 & & \\
\hline Control fish dying as delayed mortality & $n_{C}(1)$ & 2 & 1 & & \\
\hline Delayed mortality of held tournament fish & $M_{T}$ & 0.300 & 0.200 & & 2 \\
\hline Delayed mortality of held control fish & $M_{C}$ & 0.067 & 0.033 & & 3 \\
\hline Variance of delayed mortality of tournament fish & $\operatorname{Var}\left(M_{T}\right)$ & 0.0070 & 0.0053 & & 7 \\
\hline Variance of delayed mortality of control fish & $\operatorname{Var}\left(M_{C}\right)$ & 0.0021 & 0.0011 & & 8 \\
\hline Delayed mortality adjusted for control fish & $M_{D(T)}$ & 0.233 & 0.167 & & 4 \\
\hline Pooled (across days) delayed mortality & $M_{D(T)}$, total & & & 0.203 & $16^{\mathrm{a}}$ \\
\hline Variance of delayed mortality & $\operatorname{Var}\left(M_{D(T)}\right)$ & 0.0091 & 0.0064 & & 6 \\
\hline Pooled variance of delayed mortality & $\operatorname{Var}\left(M_{D(T)}\right.$, total $)$ & & & 0.0040 & $17^{\mathrm{b}}$ \\
\hline Standard error of delayed mortality & $\operatorname{SE}\left(M_{D(T)}\right)$ & 0.0953 & 0.0800 & & \\
\hline Standard error of pooled delayed mortality & $\mathrm{SE}\left(M_{D(T)}\right.$, total $)$ & & & 0.0636 & \\
\hline Total mortality & $M_{(T)}$ & 0.360 & 0.242 & & 12 \\
\hline Pooled (across days) total mortality & $M_{(T)}$, total & & & 0.310 & 16 \\
\hline Variance of total mortality & $\operatorname{Var}\left(M_{.(T)}\right)$ & 0.0063 & 0.0053 & & 15 \\
\hline Pooled variance of total mortality & $\operatorname{Var}\left(M_{.(T)}\right.$, total $)$ & & & 0.0030 & 17 \\
\hline Standard error of total mortality & $\operatorname{SE}\left(M_{.(T)}\right)$ & 0.0795 & 0.0728 & & \\
\hline Standard error of pooled (across days) total mortality & $\operatorname{SE}\left(M_{.(T)}\right.$, total $)$ & & & 0.0551 & \\
\hline
\end{tabular}

a Obtained by substituting estimates of $M_{D(T), i}$ for $M_{.(T), i}$ in equation (16).

b Obtained by substituting estimates of $M_{D(T), i}$ for $M_{.(T), i}$ in equation (17).

fish are captured and brought to weigh-in; 1,050 of these fish are alive and 208 are judged to be dead. A sample of 30 live, tournament-caught fish is transported to a holding pen (pen A) to be observed for the next $6 \mathrm{~d}$. An additional 30 fish captured by electrofishing are placed in the pen to serve as controls for pen mortality.

On day 2 of the tournament, 938 fish are captured and brought to weigh-in; 853 are alive and 85 are judged to be dead. Again, a sample of 30 live, tournament-caught fish is transported to a holding pen (pen B), into which 30 control fish are added.

After $6 \mathrm{~d}$, nine tournament-caught fish in pen A have died, as have two control fish. After $6 \mathrm{~d}$, six fish in pen B have died, as has one control fish. The results for our hypothetical tournament are shown in Table 1.

Calculating initial mortality $M_{I(T)}$ for any given day $i$ of this hypothetical tournament is straightforward:

$$
M_{I(T), i}=\frac{n_{I(T), i}}{N_{(T), i}}
$$

where $n_{I(T), i}$ is the number of fish brought to weighin dead and $N_{(T), i}$ is the total number of fish, live or dead, that are captured and brought to weighin.

Estimating delayed mortality $M_{D(T)}$ and total mortality $M_{\text {.(T) }}$ for each day of the tournament, as well as for the entire event, first requires a decision about whether to correct for mortality among control fish and then a decision as to how to correct for that mortality. Two approaches have been used. In the first approach, a subjective evaluation is made regarding the magnitude of control mortality $M_{C}$, which often is quite low, and in most cases no correction is made. In the second approach, regardless of the relative magnitude of delayed mortality $M_{T}$ between tournament-caught fish held for observation and control fish, mortality of control fish is subtracted from that of tournamentcaught fish. $M_{T, i}$ and $M_{C, i}$ are estimated as

$$
\begin{aligned}
& \hat{M}_{T, i}=\frac{n_{T(T), i}}{N_{T(T), i}} \text { and } \\
& \hat{M}_{C, i}=\frac{n_{C, i}}{N_{C, i}}
\end{aligned}
$$


where $n_{T(T), i}$ is the number of tournament-caught fish captured and held for delayed mortality observation on the $i$ th day that die during the observation period, $N_{T(T), i}$ is the total number of tournament-caught fish collected for observation on the $i$ th day, $n_{C, i}$ is the number of control fish for the $i$ th day that die during the observation period, and $N_{C, i}$ is the total number of control fish collected for observation on the $i$ th day.

Two models can be used to adjust for the mortality of control fish. The first model assumes that $M_{T}$ and $M_{C}$ are independent and that $M_{T}$ includes delayed tournament mortality effects and pen mortality. This is the simplest model and yields an estimate of delayed mortality $M_{D(T)}$, corrected for control mortality by subtraction: $M_{D(T)}=M_{T}-$ $M_{\mathrm{C}}$. The second model assumes that $M_{T}$ and $M_{C}$ are not independent and that $M_{T}$ includes tournament mortality, pen mortality, and extra mortality of tournament fish attributable to the added stress of confinement (interaction between tournament mortality and pen mortality). The second model probably is more realistic than the first, but information on the specific form of the added mortality component (if it does exist) usually is lacking, so we recommend using the simpler (first) model. Delayed mortality for any day $i$ of the tournament can then be estimated as

$$
\hat{M}_{D(T), i}=\hat{M}_{T, i}-\hat{M}_{C, i},
$$

where $\hat{M}_{T, i}$ is the mortality of tournament-caught fish captured and held for observation on the $i$ th day and $\hat{M}_{C, i}$ is the mortality of control fish collected and held on the $i$ th day.

The variance of the difference between two random variables, $X$ and $Y$, is given by $\operatorname{Var}(X-Y)$ $=\operatorname{Var}(X)+\operatorname{Var}(Y)-2 \times \operatorname{Cov}(X, Y)$, where $\operatorname{Cov}(X$, $Y$ ) is the covariance of $X$ and $Y$ (Mood et al. 1974; Larson 1982). Therefore, the variance of delayed mortality $M_{D(T)}$ for day $i$ can be estimated as

$$
\begin{aligned}
\widehat{\operatorname{Var}}\left(M_{D(T), i}\right)= & \widehat{\operatorname{Var}}\left(M_{T, i}\right)+\widehat{\operatorname{Var}}\left(M_{C, i}\right) \\
& -2 \times \widehat{\operatorname{Cov}}\left(M_{T, i}, M_{C, i}\right),
\end{aligned}
$$

where $\widehat{\operatorname{Var}}\left(M_{T, i}\right)$ is the variance of mortality of tournament-caught fish collected for observation on the $i$ th day of the tournament, $\widehat{\operatorname{Var}}\left(M_{C, i}\right)$ is the variance of mortality of control fish collected for observation on day $i$, and $\widehat{\operatorname{Cov}}\left(M_{T, i}, M_{C, i}\right)$ is the covariance between the two sources of mortality. Because $M_{T, i}$ and $M_{C, i}$ are assumed to be independent,
$\widehat{\operatorname{Cov}}\left(M_{T, i}, M_{C, i}\right)=0$. Therefore, $\widehat{\operatorname{Var}}\left(M_{D(T), i}\right)$ simplifies to:

$$
\widehat{\operatorname{Var}}\left(M_{D(T), i}\right)=\widehat{\operatorname{Var}}\left(M_{T, i}\right)+\widehat{\operatorname{Var}}\left(M_{C, i}\right)
$$

The mortality of tournament-caught fish $\left(M_{T}\right)$ and that of control fish $\left(M_{C}\right)$ are binomial variables, the variances of which correspond to the general form $\operatorname{Var}(P)=[(P) \times(1-P)] / N$, where $P$ is the proportion of fish that die (Mood et al. 1974; Larson 1982). Therefore, the variances of $M_{T, i}$ and $M_{C, i}$, respectively, can be estimated as

$$
\begin{aligned}
& \widehat{\operatorname{Var}}\left(M_{T, i}\right)=\frac{\left(\hat{M}_{T, i}\right) \times\left(1-\hat{M}_{T, i}\right)}{N_{T(T), i}} \text { and } \\
& \widehat{\operatorname{Var}}\left(M_{C, i}\right)=\frac{\left(\hat{M}_{C, i}\right) \times\left(1-\hat{M}_{C, i}\right)}{N_{C, i}} .
\end{aligned}
$$

Equation (7) should be used only if the proportion of tournament-caught fish held for observation is less than $10 \%$ of the total number of live fish $\left(n_{L(T)}\right)$ brought to weigh-in on each day of the tournament (Cochran 1977; Thompson 1992). If this proportion exceeds $10 \%$, a finite population correction (FPC) should be applied to $\operatorname{Var}\left(M_{T, i}\right)$ because the sample of tournament-caught fish $N_{T(T)}$ is large relative to the population of fish that are live at weigh-in. The FPC need not be applied to the estimate of $\operatorname{Var}\left(M_{C, i}\right)$ because we assume that only a small proportion of the total population (in the lake) is captured and held for observation as controls.

Including the FPC, the variance for the estimate of delayed mortality of tournament-caught fish held for delayed mortality observation on day $i$, $\operatorname{Var}\left(M_{T, i}\right)$, is estimated as

$$
\widehat{\operatorname{Var}}\left(M_{T, i}\right)=\frac{\left(N_{(T), i}-N_{T(T), i}\right)}{N_{(T), i}} \times \frac{\left(\hat{M}_{T, i}\right) \times\left(1-\hat{M}_{T, i}\right)}{N_{T(T), i}},
$$

where $\left(N_{(T), i}-N_{T(T), i}\right) / N_{(T), i}$ is the FPC and represents the total number of fish caught and brought to weigh-in on day $i$ minus the number of those collected for delayed-mortality observation on day $i$, divided by the total number brought to weighin on day $i$. Omitting the FPC results in an overestimate of $\operatorname{Var}\left(M_{T, i}\right)$.

Combining equation (6) and equation (9) results in 


$$
\begin{aligned}
\widehat{\operatorname{Var}}\left(M_{D(T), i}\right)= & \frac{\left(N_{(T), i}-N_{T(T), i}\right)}{N_{(T), i}} \\
& \times \frac{\left(\hat{M}_{T, i}\right) \times\left(1-\hat{M}_{T, i}\right)}{N_{T(T), i}}+\widehat{\operatorname{Var}}\left(M_{C, i}\right),
\end{aligned}
$$

which allows estimation of the variance of delayed mortality with the FPC included.

Next, estimates of initial mortality and delayed mortality, adjusted for the mortality of control fish, are combined to provide an estimate of total mortality. One commonly used method for combining these estimates, which we refer to as the naive method, is by simple addition:

$$
\hat{M}_{\cdot(T), i}=\hat{M}_{I(T), i}+\hat{M}_{D(T), i} .
$$

The naive method is flawed because it fails to recognize the conditional relationship between initial and delayed mortality. Only those fish surviving capture, handling, and weigh-in can be included in an assessment of delayed mortality. Consequently, the observed delayed mortality is applicable only to fish that survive tournament weigh-in, not to all fish as implied by the naive method. As an example, consider the case in which $M_{I(T)}=60 \%$ and $M_{D(T)}=60 \%$. The naive method, involving simple addition of the two forms of mortality, yields a nonsensical estimate of $120 \%$. The correct method would combine $M_{I(T)}(60 \%)$ with the product of $M_{D(T)}(60 \%)$ and the proportion of fish that survived weigh-in $(40 \%)$ to yield the correct estimate of $84 \%$ (Mood et al. 1974; Larson 1982). The naive method usually will overestimate total mortality.

Total mortality $M_{\text {.(T) }}$ for any given day $i$ of the tournament is correctly estimated as

$$
\hat{M}_{(T), i}=M_{I(T), i}+\left[\left(\frac{n_{L(T), i}}{N_{(T), i}}\right) \times \hat{M}_{D(T), i}\right],
$$

where $M_{I(T)}$ is initial mortality on the $i$ th day, $M_{D(T)}$ is delayed mortality of fish captured on the $i$ th day, $n_{L(T), i}$ is the number of fish brought to weigh-in alive, and $N_{(T), i}$ is the total number of fish, live or dead, that are captured and brought to weigh-in.

The variance of the sum of two random variables, $X$ and $Y$, is $\operatorname{Var}(X+Y)=\operatorname{Var}(X)+\operatorname{Var}(Y)$ $+2 \times \operatorname{Cov}(X, Y)($ Mood et al. 1974; Larson 1982). Thus, the sampling variance for total mortality, $\operatorname{Var}\left(M_{.(T)}\right)$, is estimated as

$$
\begin{aligned}
\widehat{\operatorname{Var}}\left(M_{.(T), i}\right)= & \widehat{\operatorname{Var}}\left(M_{I(T), i}\right)+\widehat{\operatorname{Var}}\left[\left(\frac{n_{L(T), i}}{N_{(T), i}}\right) \times M_{D(T), i}\right] \\
& +2 \times \widehat{\operatorname{Cov}}\left(M_{I(T), i}, M_{D(T), i}\right),
\end{aligned}
$$

where $\widehat{\operatorname{Var}}\left(M_{I(T), i}\right)$ is the variance of initial mortality, $\operatorname{Var}\left[\left(n_{L(T), i} / N_{(T), i}\right) \times M_{D(T), i}\right]$ is the variance of delayed mortality estimated in equation (10) weighted by $\left(n_{L(T), i} / N_{(T), i}\right)$, the number of fish live at weigh-in on day $i$ divided by the total number brought to weigh-in on that day, and $\operatorname{Cov}\left(M_{I(T), i}\right.$, $\left.M_{D(T), i}\right)$ is the covariance between initial and delayed mortality. Because we know exactly how many fish were brought to weigh-in and how many were dead and alive at that time, initial mortality is measured without error, and therefore $\operatorname{Var}\left(M_{I(T), i}\right)=0$. Furthermore, because initial and delayed mortality are uncorrelated (Wilde 1998), $\operatorname{Cov}\left(M_{I(T), i}, M_{D(T), i}\right)=0$. Consequently, equation (13) simplifies to

$$
\widehat{\operatorname{Var}}\left(M_{.(T), i}\right)=\widehat{\operatorname{Var}}\left[\left(\frac{n_{L(T), i}}{N_{(T), i}}\right) \times M_{D(T), i}\right] .
$$

Further, because the variance of a variable $X$ multiplied by a quantity $b$ is equal to the variance of $X$ multiplied by $b^{2}$, that is, $\operatorname{Var}(b \times X)=b^{2} \times$ $\operatorname{Var}(X)($ Mood et al. 1974; Larson 1982), we can restate equation (14) as

$$
\widehat{\operatorname{Var}}\left(M_{.(T), i}\right)=\left(\frac{n_{L(T), i}}{N_{(T), i}}\right)^{2} \times \widehat{\operatorname{Var}}\left(M_{D(T), i}\right) .
$$

Thus, $\widehat{\operatorname{Var}}\left(M_{(T), i}\right)$ is easily estimated, given an estimate of $\widehat{\operatorname{Var}}\left(M_{D(T), i}\right)$ (see equation 6) and knowledge of the number of fish brought to weighin live $\left(n_{L(T), i}\right)$ and the total number of fish, dead or alive, captured and brought to weigh-in $\left(N_{(T), i}\right)$. The standard error of $M_{.(T), i}$ is estimated as the square root of $\operatorname{Var}\left(M_{.(T), i}\right)$ (Mood et al. 1974; Larson 1982).

We now consider the case of tournaments that are longer than $1 \mathrm{~d}$, in which $1<n<N$ days are sampled. There are two basic scenarios: we measure $M_{\text {.(T) }}$ on each of the $n=N$ days of the tournament, or we measure $M_{\text {.(T) }}$ on a sample of $n<$ $N$ days. Calculation of the sampling variance of total mortality across all days of the tournament $\left(M_{\text {(T),total }}\right)$ is straightforward unless either of the following is true:

(1) because initial mortality is easily measured, we have measurements of $M_{I(T)}$ on $n$ days of the tournament but estimates of $M_{D(T)}$ for only $m<n$ days, or

(2) both $M_{I(T)}$ and $M_{D(T)}$ are measured on only $n$ days, but these days are not chosen at random.

In the first scenario, the sampling variance of $M_{\text {.(T) }}$ can be estimated by simple modification of 
the formulae presented below. In the second scenario, there is no simple method for estimating the sampling variance of $M_{\text {.(T) }}$ because of the failure to randomize.

If estimates of $M_{.(T)}$ are available for all $N$ days of the tournament, we can treat days as strata and consider this to be a simple sampling problem with unequal allocation of catch among days. Formulae for estimating the mean $M_{\text {.(T),total }}$ and sampling variance $\operatorname{Var}\left(M_{.(T), \text { total }}\right)$ of total mortality across all days of the tournament can be obtained from any sampling text, such as Cochran (1977) or Thompson (1992):

$$
\begin{aligned}
\hat{M}_{.(T), \text { total }} & =\sum W_{i} \times \hat{M}_{.(T), i} \text { and } \\
\widehat{\operatorname{Var}}\left(M_{.(T), \text { total }}\right) & =\sum W_{i}^{2} \times \widehat{\operatorname{Var}}\left(M_{.(T), i}\right),
\end{aligned}
$$

where $M_{.(T), i}$ is total mortality on the $i$ th tournament day and $W_{i}$ is a weighting factor equal to $N_{(T), i} I$ $N_{(T) \text {,total }}$, the number of fish captured and brought to weigh-in on the $i$ th day divided by the total number of fish captured on all $N$ days of the tournament. $W_{i}$ is squared $\left(W_{i}^{2}\right)$ in equation (17) because, as mentioned previously, $\operatorname{Var}(b \times X)=b^{2}$ $\times \operatorname{Var}(X)($ Mood et al. 1974; Larson 1982). Total delayed mortality across all days of the tournament, $M_{D(T), \text { total }}$, and its sampling variance can be estimated by substituting daily estimates of $M_{D(T)}$ for those of $M_{.(T)}$ in equations (16) and (17) and modifying $W_{i}$ as $/ n_{L(T), i} / n_{L(T) \text {,total }}$, where $n_{L(T), i}$ is the number of live fish brought to weigh-in on the $i$ th day and $n_{L(T) \text {,total }}$ is the total number of live fish brought to weigh-in on all days of the tournament.

If estimates of $M_{.(T)}$ are available for only $1<$ $n<N$ days of the tournament, the mean is calculated as in equation (16), and the sampling variance for total mortality across all days of the tournament is

$$
\begin{aligned}
\widehat{\operatorname{Var}}\left(M_{.(T), \text { total }}\right)= & \sum W_{i}^{2} \times \widehat{\operatorname{Var}}\left(M_{.(T), i}\right) \\
& +\sum W_{i} \times\left(\hat{M}_{(T), i}-\hat{M}_{.(T), \text { total }}\right)^{2}
\end{aligned}
$$

which is equivalent to the (pooled) across-days variance plus the between-strata (days) variance (Cochran 1977; Thompson 1992). The sampling variance of $M_{.(T)}$ in equation (18) usually will be greater than that estimated from equation (17), thereby providing an incentive to measure mortality on all $N$ days of the tournament. These formulae assume that each day is an independent observation and, in particular, that tournament catch and mortality rates on one day do not influence those on subsequent days. This assumption is reasonable when the number of fish captured in the tournament represents only a small fraction of the total population in the water(s) fished (e.g., Kwak and Henry 1995).

\section{Discussion}

The total mortality of tournament-caught fish has commonly been estimated incorrectly by use of the naive method and presented without challenge in the fisheries literature for nearly 30 years. The naive method results in an overestimate of $M_{\text {.(T) }}$ by a quantity equal to $M_{I(T)} \times M_{D(T)}$. Further, only one account of tournament-associated mortality (Wilde et al. 2002b) has presented an estimate of the standard error or confidence interval for tournament mortality. Our hope is that methods presented herein will address these shortcomings in studies of fishing-tournament mortality and thereby allow greater insight into factors affecting mortality of fishes captured in tournaments.

We believe that knowledge of the sampling variances of initial, delayed, and total mortality is important for several reasons. First, mortality is measured with error, and presentation of means without confidence intervals or variance estimates implies otherwise. Second, knowledge of the sampling variance allows one to assess the quality (precision) of mortality estimates and assess how similar, or disparate, other estimates of mortality likely would be if a given study were repeated. This bears directly on the question of how much weight one should attach to any particular estimate of mortality. Third, differences among days in the sampling variance of tournament-associated mortality may be useful in identifying ways to reduce mortality. Between-days variation in initial, delayed, and total mortality has been interpreted as showing effects of weather (Goeman 1991) and depth of capture (Wilde et al. 2002b) on mortality; the soundness of these inferences cannot be judged in the absence of any estimate of the sampling variance of mortality. For example, in our hypothetical tournament (Table 1), one could surmise that fish handling had improved from day $1\left(M_{\text {.(T) }}\right.$ $=36 \%)$ to day $2\left(M_{.(T)}=24 \%\right)$; however, there is no significant difference in total mortality between days (normal approximation $t$-test; $t=1.058$, df $=2,194, P=0.2899$ ). Better understanding of the magnitude and causes of between-days variation in the sampling variance of mortality estimates also might suggest factors that are correlated with mortality, as well as a means to reduce it. Finally, failure to estimate the sampling variance of initial, 
delayed, and total mortality may have compromised past efforts to reduce tournament-associated mortality. Wilde (1998) reported that there had been no decrease in mortality between tournaments held in the 1980s and the 1990s, despite the efforts of numerous investigators. We believe it is quite possible that previous studies, which focused exclusively on means, may have mistaken normal variation among tournaments as representing definitive changes in mortality. This might lead to the adoption of ineffective measures or the dismissal of potentially important innovations.

Because the mortality of tournament-caught fish $M_{T, i}$ and that of control fish $M_{C, i}$ commonly are estimated with small samples, it is possible to obtain a negative estimate of delayed mortality from equation (4) and, consequently, a negative estimate of total mortality $M_{\text {.(T) }}$ from equation (12). This can be handled in two ways. First, one can present the negative mortality estimates plus estimates of their sampling variances, with comment that negative estimates imply an estimate of zero. Alternatively, the negative estimates of mean mortality can be set equal to zero once all calculations are completed, with comment that this was done. Neither of these actions affects estimates of the sampling variance of delayed and total mortality because the variance of a variable $X$ is unaffected by addition or subtraction of a constant $b$ such that $\operatorname{Var}(X+b)=\operatorname{Var}(X)$ (Mood et al. 1974; Larson 1982). In this example, $b$ is the (positive) quantity added to make a negative estimate of mortality equal to zero.

The formulae presented herein are based on two assumptions. First, we assume that individual fish represent independent observations. In fact, this assumption is violated because several fish, ideally including both tournament-caught and control fish, typically are held in a single pen. In this case, individual pens are the true unit of observation. There has been, as yet, no assessment of the consequences of violating this assumption; pending such an assessment, we advise use of replicate cages. The assumption that fish represent independent observations also is violated in studies that use live wells as the unit of observation. In this case, fish within live wells are replicate observations for a given live well. Our formulae can and should be modified before use in these studies. Second, we have assumed that fish captured and brought to weigh-in at an individual tournament represent a population. However, we might instead have been interested in the general question of tournament-associated mortality where, for ex- ample, catch and mortality rates in our hypothetical tournament are only one realization of what might have occurred. In this case, $N_{(T), i}$ is an estimate of the number of fish that might be caught on each day of the tournament, and initial mortality $M_{I(T)}$ is measured with error. If we assume that the number of fish captured in the tournament is a small proportion of the total population, then no FPC is necessary, and the sampling variance of total mortality presented in equation (15) becomes

$$
\begin{aligned}
\widehat{\operatorname{Var}}\left(M_{.(T), i}\right)= & \frac{\left(\hat{M}_{I(T), i}\right) \times\left(1-\hat{M}_{I(T), i}\right)}{N_{(T), i}} \\
& +\left[W_{i}^{2} \times \widehat{\operatorname{Var}}\left(M_{D(T), i}\right)\right], \text { or } \\
\widehat{\operatorname{Var}}\left(M_{.(T), i}\right)= & \widehat{\operatorname{Var}}\left(M_{I(T), i}\right)+\left[W_{i}^{2} \times \widehat{\operatorname{Var}}\left(M_{D(T), i}\right)\right],
\end{aligned}
$$

where the term $\left[\hat{M}_{I(T), i} \times\left(1-\hat{M}_{I(T), i}\right)\right] / N_{(T), i}$ represents the binomial variance for initial mortality $\operatorname{Var}\left(M_{I(T)}\right)$. Estimates of delayed mortality and its sampling variance across all days of the tournament can be obtained by substituting daily estimates of delayed mortality for those of total mortality and modifying $W_{i}$ as described following equations (16) and (17).

The formulae for estimating the means and variances of delayed and total mortality provide guidance for the design and analysis of studies of tournament-associated and hooking mortality. Study design must be adequate to differentiate between delayed mortality associated with capture and handling of tournament-caught fish and mortality attributable to confinement in pens (or other observation structures). Studies conducted without controls have no ability to distinguish between these effects. Therefore, by design, these studies cannot detect delayed mortality and represent a waste of effort and resources. We see no benefit in conducting such studies.

In many cases, the number of tournament-caught fish exceeds, by several times, the number of control fish held for assessment of $M_{D(T)}$. Instead, analyses of the power of Fisher's exact test to discern differences between $M_{T}$ and $M_{C}$ (Table 2) show that approximately equal numbers of tournament and control fish should be used. Further, sample size of tournament-caught fish required to detect $M_{D(T)}$ of $10 \%$ exceeds the number held in many previous studies. Both tournament-associated mortality and hooking are related to water temperature in a nonlinear manner (Hoffman et al. 1996; Wilde 1998; Wilde et al. 2000). Consequently, larger 
TABLE 2.-Minimum delayed mortality detectable using Fisher's exact test assuming that $\alpha=0.15$ and $\alpha=0.10$ when various numbers of tournament-caught and control fish are held for observation. In all cases, the mortality of control fish is assumed to be $0 \%$.

\begin{tabular}{cccc}
\hline \multirow{2}{*}{$\begin{array}{c}\text { Number of } \\
\text { tournament } \\
\text { fish }\end{array}$} & $\begin{array}{c}\text { Number of } \\
\text { control } \\
\text { fish }\end{array}$ & \multicolumn{2}{c}{ Delayed mortality (\%) } \\
\cline { 3 - 4 } & 10 & 25.0 & $\alpha=0.15$ \\
\hline 20 & 20 & 15.0 & 20.0 \\
20 & 10 & 23.3 & 26.7 \\
30 & 20 & 13.3 & 16.7 \\
30 & 30 & 10.0 & 13.3 \\
30 & 10 & 22.5 & 25.0 \\
40 & 20 & 12.5 & 15.0 \\
40 & 30 & 7.5 & 10.0 \\
40 & 40 & 7.5 & 10.0 \\
40 & & & \\
\hline
\end{tabular}

samples are needed to detect a given level of mortality when water temperatures are low than when water temperatures are high.

In the case of a politically sensitive issue such as fishing tournaments, high standards for study design may be needed. A poorly designed study with little ability (statistical power) to distinguish between delayed and control mortality could, by design, make it impossible to detect delayed mortality, resulting in an underestimate of tournamentassociated mortality and its potential fishery impacts. Challenges to such poorly designed studies could threaten agency credibility (Mather et al. 1995).

\section{Recommendations}

At this time, there is no clear consensus within the fishery management community as to the magnitude of impacts associated with tournament angling. However, many anglers who do not participate in fishing tournaments believe that most released fish do not survive (Wilde et al. 1998a), and mortality at some events exceeds that viewed as acceptable even by tournament participants (Wilde et al. 2002a). Given the limitations of previous studies of tournament-associated mortality, we may "know" considerably less than generally is believed. Consequently, well-designed studies of tournament-associated mortality are needed. Previous arguments for more widespread adoption and application of the principles of experimental design in fishery studies (e.g., McAllister and Peterman 1992; Wilde and Fisher 1996) largely have gone unheard. Nevertheless, we offer several design suggestions for the conduct of future studies that will improve our knowledge of tournamentassociated mortality and the factors influencing it.
(1) First and foremost, control fish should be included in all studies, and the relative numbers of tournament and control fish should be determined based on the expected rates of mortality of tournament and control fish, so as to provide reasonable statistical power. Control fish should be collected with the least stressful method available so that, to the extent possible, control fish will provide a realistic estimate of pen mortality. Ideally, a test such as Fisher's exact test (Sokal and Rohlf 1981) should be used to assess the significance of the difference in mortality between control $\left(M_{C}\right)$ and tournament-caught fish $\left(M_{T}\right)$. Failure to include control fish prevents a formal or informal assessment of the relative magnitude of these two sources of mortality. Further, without adequate controls, one cannot conclude that mortality observed in tournament-caught fish is due to tournament handling; instead, mortality might be attributable to stressful environmental conditions or other factors.

(2) Mortality should be measured either on all days of the tournament or on a randomly selected subset of days. No method is available for calculating the correct mean and sampling variance of mortality if the subset of days sampled is not selected at random.

(3) Estimates of initial, delayed, and total mortality should be reported with estimates of their sampling variances.

(4) Tournament-caught fish that are collected and held for studies of delayed mortality should be selected at random from among those brought to weigh-in. Selection should be by one of three methods: collection of fish at random from among all captured fish (individual fish are the unit of observation); collection of a pre-selected number of fish, say one or two, at random from randomly selected live wells (fish are replicates [nested] within live wells, which are the units of observation); or collection of all fish from randomly selected live wells (live wells are the units of observation). Methods by which fish are selected should be described in detail.

(5) Evaluations of innovative handling methods, live-well additives, or other practices that might affect tournament-associated mortality also should adhere to these general guidelines.

\section{Acknowledgments}

We thank S. Gutreuter for helpful discussions. S. Gutreuter, K.G. Ostrand, and W. Schlechte commented on the manuscript. This is contribution T- 
09-922 of the College of Agricultural Sciences and Natural Resources, Texas Tech University.

\section{References}

Barnhart, R. A. 1989. Symposium review: catch-andrelease fishing, a decade of experience. North American Journal of Fisheries Management 9:74-80.

Cochran, W. G. 1977. Sampling techniques, 3rd edition. Wiley, New York.

Duttweiler, M. W. 1985. Status of competitive fishing in the United States: trends and state fisheries policies. Fisheries 10(5):5-7.

Fielder, D. G., and B. A. Johnson. 1994. Walleye mortality during live-release tournaments on Lake Oahe, South Dakota. North American Journal of Fisheries Management 14:776-780.

Gilliland, G. 1997. Evaluation of procedures to reduce delayed mortality of black bass following summer tournaments. Oklahoma Department of Wildlife Conservation, Job Performance Report, Federal Aid Project F-50-R, Oklahoma City.

Goeman, T. J. 1991. Walleye mortality during a liverelease tournament on Mills Lac, Minnesota. North American Journal of Fisheries Management 11:5761.

Hoffman, G. C., D. W. Coble, R. V. Frie, F. A. Copes, R. M. Bruch, and K. K. Kamke. 1996. Walleye and sauger mortality associated with live-release tournaments on the Lake Winnebago system, Wisconsin. North American Journal of Fisheries Management 16:364-370.

Holbrook, J. A., II. 1975. Bass fishing tournaments. Pages 408-414 in H. Clepper, editor. Black bass biology and management. Sport Fishing Institute, Washington, D.C.

Kwak, T. J., and M. G. Henry. 1995. Largemouth bass mortality and related causal factors during liverelease fishing tournaments on a large Minnesota lake. North American Journal of Fisheries Management 15:621-630.

Larson, H. J. 1982. Introduction to probability theory and statistical inference. Wiley, New York.

Mather, M. E., D. L. Parrish, R. A. Stein, and R. M. Muth. 1995. Management issues and their relative priority within state fisheries agencies. Fisheries 20(10):14-21.

May, B. E. 1973. Evaluation of largescale release programs with special reference to bass fishing tournaments. Proceedings of the Annual Conference Southeastern Association of Game Fish Commissioners 26(1972):325-334.

McAllister, K. M., and R. M. Peterman. 1992. Experi- mental design in the management of fisheries. North American Journal of Fisheries Management 12:118.

Mood, A. M., F. A. Graybill, and D. C. Boes. 1974. Introduction to the theory of statistics. McGrawHill, New York.

Muoneke, M. I., and W. M. Childress. 1994. Hooking mortality: a review for recreational fisheries. Reviews in Fisheries Science 2:123-156.

Schramm, H. L., Jr., P. J. Haydt, and N. A. Bruno. 1985. Survival of tournament-caught largemouth bass in two Florida lakes. North American Journal of Fisheries Management 5:606-611.

Schramm, H. L., Jr., M. L. Armstrong, N. A. Funicelli, D. M. Green, D. P. Lee, R. E. Manns, Jr., B. D. Taubert, and S. J. Waters. 1991. The status of competitive fishing in North America. Fisheries 16(3): 4-12.

Shupp, B. D. 1979. 1978 status of bass fishing tournaments in the United States. Fisheries 4(6):11-19.

Sokal, R. R., and F. J. Rohlf. 1981. Biometry, 2nd edition. Freeman, San Francisco.

Thompson, S. K. 1992. Sampling. Wiley, New York.

Wilde, G. R. 1998. Tournament-associated mortality in black bass. Fisheries 23(10):12-22.

Wilde, G. R., and W. L. Fisher. 1996. Reservoir fisheries and sampling design. Pages 397-409 in L. E. Miranda and D. R. DeVries, editors. Multidimensional approaches to reservoir fisheries management. American Fisheries Society, Symposium 16, Bethesda, Maryland.

Wilde, G. R., D. H. Larson, W. H. Redell, and G. R. Wilde III. 2002a. Mortality of black bass in three Texas fishing tournaments. Texas Journal of Science 54:125-132.

Wilde, G. R., C. E. Shavlik, and K. L. Pope. 2002b. Initial mortality of black bass in B. A. S. S. fishing tournaments North American Journal of Fisheries Management 22:950-954.

Wilde, G. R., M. I. Muoneke, P. W. Bettoli, K. L. Nelson, and B. T. Hysmith. 2000. Bait and temperature effects on striped bass hooking mortality in freshwater. North American Journal of Fisheries Management 20:810-815.

Wilde, G. R., R. K. Riechers, and R. B. Ditton. 1998a. Differences in attitudes, fishing motives, and demographic characteristics between tournament and nontournament black bass anglers in Texas. North American Journal of Fisheries Management 18: 422-431.

Wilde, G. R., D. W. Strickland, K. G. Ostrand, and M. I. Muoneke. 1998b. Characteristics of Texas black bass fishing tournaments. North American Journal of Fisheries Management 18:972-977. 